\title{
\begin{tabular}{l|l} 
Mitraries & DSpace@MIT
\end{tabular}
}

\author{
MIT Open Access Articles
}

\section{Palladium-Catalyzed Intramolecular C-H Difluoroalkylation: Synthesis of Substituted 3,3-Difluoro-2-oxindoles}

The MIT Faculty has made this article openly available. Please share how this access benefits you. Your story matters.

Citation: Shi, Shi-Liang, and Stephen L. Buchwald. “Palladium-Catalyzed Intramolecular C-H Difluoroalkylation: Synthesis of Substituted 3,3-Difluoro-2-Oxindoles." Angew. Chem. Int. Ed. 54, no. 5 (December 4, 2014): 1646-1650.

As Published: http://dx.doi.org/10.1002/anie.201410471

Publisher: Wiley Blackwell

Persistent URL: http://hdl.handle.net/1721.1/99673

Version: Author's final manuscript: final author's manuscript post peer review, without publisher's formatting or copy editing

Terms of use: Creative Commons Attribution-Noncommercial-Share Alike 


\title{
Palladium-Catalyzed Intramolecular C-H Difluoroalkyation: The Synthesis of Substituted 3,3-Difluoro-2-oxindoles*
}

\author{
Dr. Shi-Liang Shi and Prof. Dr. Stephen L. Buchwald \\ Department of Chemistry, Room 18-490, Massachusetts Institute of Technology, Cambridge, MA \\ 02139 (USA) \\ Stephen L. Buchwald: sbuchwal@mit.edu
}

\begin{abstract}
The synthesis of 3,3-difluoro-2-oxindoles through a robust and efficient palladium-catalyzed $\mathrm{C}-\mathrm{H}$ difluoroalkylation is described. This process generates a broad range of difluorooxindoles from readily prepared starting materials. The use of BrettPhos as the ligand was crucial for high efficiency. Preliminary mechanistic studies suggest that oxidative addition is the rate-determining step for this process.
\end{abstract}

\section{Keywords}

$\mathrm{C}-\mathrm{H}$ difluoroalkylation; palladium catalysis; fluorine; cross-coupling; heterocycles

The incorporation of fluorinated functional groups into organic molecules has been widely recognized as a general strategy in pharmaceutical research and drug development. Fluorinated analogues of pharmaceutically relevant compounds often possess properties conducive to drug development, such as improved lipophilicity, metabolic stability, and bioavailability relative to their nonfluorinated counterparts. ${ }^{[1]}$ For these reasons, substantial effort has been devoted to the development of synthetic methods for the assembly of fluorinated small molecules. ${ }^{[2]}$ The fluorination ${ }^{[3]}$ and trifluoromethylation ${ }^{[4]}$ of arenes have been the most prominent targets of these efforts, and as a result, increasingly general and practical methods are now available for these transformations. ${ }^{[2]}$ In contrast, methods for the synthesis of difluoroalkylated arenes remain limited. ${ }^{[5]}$ In particular, the synthesis of fluorinated heterocyclic compounds by the difluoroalkylation of arenes is a promising but underutilized strategy.

Derivatives of oxindole and isatin appear in a variety of naturally occurring and synthetic bioactive compounds (Figure 1). ${ }^{[6]}$ As bioisoteric analogs ${ }^{[7]}$ of both classes of heterocycles, compounds containing the 3,3-difluoro-2-oxindole ring system have demonstrated

\footnotetext{
** We thank the National Institutes of Health for financial support (GM46059). The content is solely the responsibility of the authors and does not necessarily represent the official views of the National Institutes of Health. S.-L.Shi thanks JSPS for a fellowship. We thank Dr. Yiming Wang, Dr. Michael Pirnot and Dr. Daniel T. Cohen for assistance with the preparation of this manuscript.

(c) 2013 Wiley-VCH Verlay GmbH \& Co. KGaA, Weinheim

Correspondence to: Stephen L. Buchwald, sbuchwal@mit . edu.

Supporting information for this article is available on the WWW under http://dx.doi.org/10.1002/anie.201xxxxxx.
} 
considerable promise as potential medicinal agents. ${ }^{[8]}$ There are, however, only a limited number of approaches for their preparation, each of which suffers from serious drawbacks. ${ }^{[9]}$ Difluorooxindoles have been prepared by the treatment of isatin derivatives with diethylaminosulfur trifluoride (DAST) or by electrophilic fluorination of indoles. ${ }^{[9 a-c]}$ However, the limited stability of the requisite reagents and modest functional group tolerance diminish the utility and practicality of these procedures ${ }^{[10]}$ Moreover, both approaches depend on the availability of the pre-existing bicyclic ring system, whose construction may be nontrivial. The de novo synthesis of the difluorooxindole ring system under free radical conditions ${ }^{[9 \mathrm{~d}]}$ or in the presence of a stoichiometric amount of copper ${ }^{[9 \mathrm{e}]}$ has also been reported. However, these methods are limited by their scope, synthetic efficiency, or the accessibility of the required starting materials. A synthesis of difluorooxindoles through a palladium-catalyzed $\mathrm{C}-\mathrm{H}$ difluoroalkylation process ${ }^{[11]}$ would constitute a general and practical alternative to these previously reported methods.

In 2003, we disclosed the palladium-catalyzed synthesis of oxindoles from achloroacetanilides. ${ }^{[12]}$ The application of this method to the kilogram-scale synthesis of two drug candidates, a serine palmitoyl transferase inhibitor $(\mathbf{3})^{[13]}$ and a long-term oxazolidinone antibacterial $(\mathbf{4})^{[14]}$ illustrate the practicality and atom- and step-economical advantages of this $\mathrm{C}-\mathrm{H}$ functionalization protocol. An analogous process wherein chlorodifluoroacetanilides are transformed to difluorooxindoles would similarly enable the rapid construction of these compounds from readily available starting materials; chlorodifluoroacetanilides can be prepared in one step by acylation of the corresponding (hetero)arylamines with inexpensive chlorodifluoroacetic anhydride. Although the oxidative addition $^{[15]}$ of $\mathrm{Pd}(0)$ to the analogous $\mathrm{C}-\mathrm{Cl}$ bond of chlorodifluoroacetanilides, as well as the subsequent $\mathrm{C}-\mathrm{C}$ bond forming reductive elimination ${ }^{[4 a, 16]}$ are expected to be challenging processes, we posited that the use of bulky biarylphosphine ligands would facilitate these elementary steps. We disclose herein the successful development of an efficient palladium-catalyzed $\mathrm{C}-\mathrm{H}$ difluoroalkylation reaction for the synthesis of 3,3difluoro-2-oxindoles.

We began our investigation of the proposed transformation by exposing chlorodifluoroacetanilide 1a to base $\left(\mathrm{K}_{2} \mathrm{CO}_{3}\right)$ and palladium catalysts generated from premixing ${ }^{[17]} 1 \mathrm{~mol} \%$ of $\mathrm{Pd}_{2} \mathrm{dba}_{3}$ and $4 \mathrm{~mol} \%$ of a variety of phosphine ligands. The use of JohnPhos (L1), the optimal ligand for the previous oxindole synthesis, provided 2a in low yield (entry 1). Catalysts derived from CyJohnPhos (L2), RuPhos (L3), XPhos (L4) and $t$ BuXPhos (L5) were more effective, but still only provided the desired oxindole in low to moderate yields (entries 2-5). However, when BrettPhos (L6) was employed as the ligand, difluorinated oxindole 2a was isolated in high yield (78\%, entry 6). The use of other monophosphine ligands, as well as bidentate phosphine ligands, such as $\mathrm{PPh}_{3}, \mathrm{PCy}_{3}$, $\mathrm{P}(t \mathrm{Bu})_{3}$, dppe, BINAP and Xantphos, resulted in low to no conversion to the desired product (entries 7-12). No conversion of the starting material was observed in the absence of either phosphine ligand or palladium source (entries 13 and 14). Lastly, exposure of 1a to FriedelCrafts cyclization conditions ( 1.2 equiv $\mathrm{AlCl}_{3}$ ) led to the decomposition of the starting material without formation of the desired product. 
Under optimized conditions (Table 2), we explored the substrate scope of this transformation. A series of chlorodifluoroacetanilides with electron-rich, -neutral, and deficient substituents on the aryl group were found to undergo the desired transformation to afford the corresponding difluorooxindoles in good yield. This process was found to be compatible with ketone (2h), ester (2g), amide (2i), acetal (2i), hemiaminal (2b), amino (2d, $\mathbf{2 e}$ ), and trifluoromethoxy (2f) functional groups.

Given the prevalence of heterocycles in medicinal chemistry, we also investigated the scope of heterocyclic substrates. ${ }^{[18]}$ A broad array of heterocycle substrates featuring monocyclic, bicyclic, and tricyclic ring were compatible with the optimized reaction conditions. The scope included heterocycles such as pyridine (2k), tetrahydroquinoline (2m, 2o), 1,4benzoxazine (2n), dihydrophenanthridine (2q), dihydroquinolinone (2p), tetrahydrobenzazepine (2r), dihydrodibenzoazepine (2s), tetrahydrobenzooxazepine (2t), tetrahydrobenzothioazepine (2x), and tetrahydrobenzodiazepine (2y) ring systems. Unsymmetrical indole and carbazole substrates provided products $\mathbf{2} \mathbf{j}$ and $\mathbf{2} \mathbf{l}$ as chromatographically separable regioisomers with moderate selectivity. Interestingly, the cyclization occurred preferentially at the more sterically hindered position of these substrates, in contrast to our previous palladium-catalyzed oxindole synthesis. ${ }^{[12]}$ To demonstrate the robustness of our conditions, the synthesis of $\mathbf{2 t}$ was also conducted on a 5 mmol scale to afford the desired product in undiminished isolated yield.

To probe the mechanism of this transformation, we synthesized isotopically-labeled substrates $\mathbf{1 a}-d_{1}$ and 1a- $d_{5}$ (Scheme 1) for the determination of the intra- and intermolecular kinetic isotope effects, respectively. An inverse kinetic isotope effect was observed when 1a- $d_{1}$ was subjected to standard reaction conditions $\left(k_{\mathrm{H}} / k_{\mathrm{D}}=0.79\right.$, eq 1$)$. On the other hand, no kinetic isotope effect was observed upon exposure of a 1:1 mixture of 1a and 1a- $d_{5}$ to the standard reaction conditions $\left(k_{\mathrm{H}} / k_{\mathrm{D}}=1.01\right.$, eq 2$)$.

Based on these data, a plausible mechanism for this transformation is shown in Scheme 2. The initial step of this process is likely oxidative addition of the chlorodifluoro amide to $\operatorname{Pd}(0)$ to generate a $\mathrm{Pd}(\mathrm{II})$ enolate. The absence an intermolecular isotope effect indicates that the rate-determining step occurs prior to a $\mathrm{C}-\mathrm{H}$ bond cleavage or rehybridization event, suggesting that oxidative addition is rate-determining. ${ }^{[19]}$ Subsequently, electrophilic aromatic substitution of the arene furnishes a six-membered palladacycle, which then undergoes reductive elimination to provide the observed product and regenerate the $\operatorname{Pd}(0)$ species. The inverse kinetic isotope effect observed in the intramolecular experiment is likely a secondary isotope effect resulting from the $\mathrm{sp}^{2}$ to $\mathrm{sp}^{3}$ rehybridization of the arene carbon to which the proton or deuteron is attached. ${ }^{[20]}$ The observation of an inverse isotope effect implies that palladation is slow relative to $\mathrm{C}-\mathrm{H}$ bond cleavage in the electrophilic aromatic substitution process, in contrast to our previously reported palladium-catalyzed oxindole synthesis from a-chloroacetanilides. ${ }^{[12]}$ Alternative mechanisms in which palladation occurs through concerted metalation-deprotonation or $\sigma$-bond metathesis pathways are excluded on the basis of the observed inverse intramolecular isotope effect. ${ }^{[21]}$

In summary, we have developed a practical palladium-catalyzed aromatic $\mathrm{C}-\mathrm{H}$ difluoroalkylation reaction using readily available chlorodifluoroacetanilides. The bulky 
biarylphosphine ligand, BrettPhos, was found to be the only phosphine ligand capable of efficiently providing the desired difluorooxindole product. This method allows for the straightforward and efficient preparation of a wide range of substituted 3,3-difluoro-2oxindoles. The high level of functional group tolerance and ready availability of starting materials should make this protocol broadly useful and attractive in academic and industrial settings.

\section{Supplementary Material}

Refer to Web version on PubMed Central for supplementary material.

\section{References}

1. a) Müller K, Faeh C, Diederich F. Science. 2007; 317:1881-1886. [PubMed: 17901324] b) Hiyama, T. Fluorine Compounds: Chemistry and Applications. Springer; Berlin: 2000. c) Yamazaki, T.; Taguchi, T.; Ojima, I. Fluorine in Medicinal Chemistry and Chemical Biology. Ojima, I., editor. Wiley-Blackwell; Chichester: 2009. p. 3-46.d) Purser S, Moore PR, Swallow S, Gouverneur V. Chem Soc Rev. 2008; 37:320-330. [PubMed: 18197348] e) Wang J, Sánchez-Roselló M, Aceña JL, del Pozo C, Sorochinsky AE, Fustero S, Soloshonok VA, Liu H. Chem Rev. 2014; 114:2432-2506. [PubMed: 24299176]

2. For selected reviews, see: Liang T, Neumann CN, Ritter T. Angew Chem Int Ed. 2013; 52:82148264.Tomashenko OA, Grushin VV. Chem Rev. 2011; 111:4475-4521. [PubMed: 21456523] Besset T, Schneider C, Cahard D. Angew Chem Int Ed. 2012; 51:5048-5050.Wu XF, Neumann H, Beller M. Chem Asian J. 2012; 7:1744-1754. [PubMed: 22715145] Lundgren RJ, Stradiotto M. Angew Chem Int Ed. 2010; 49:9322-9324.For selected examples of arene fluorination and trifluoromethylation, see: Nagib DA, MacMillan DWC. Nature. 2011; 480:224-228. [PubMed: 22158245] Ji Y, Brueckl T, Baxter RD, Fujiwara Y, Seiple IB, Su S, Blackmond DG, Baran PS. Proc Natl Acad Sci USA. 2011; 108:14411-14415. [PubMed: 21844378] Tang P, Furuya T, Ritter T. J Am Chem Soc. 2010; 132:12150-12154. [PubMed: 20695434] Wang X, Truesdale L, Yu JQ. J Am Chem Soc. 2010; 132:3648-3649. [PubMed: 20184319] Ball ND, Kampf JW, Sanford MS. J Am Chem Soc. 2010; 132:2878-2879. [PubMed: 20155920] Chu L, Qing FL. J Am Chem Soc. 2012; 134:1298-1304. [PubMed: 22145831]

3. a) Watson DA, Su M, Teverovskiy G, Zhang Y, García-Fortanet J, Kinzel T, Buchwald SL. Science. 2009; 325:1661-1664. [PubMed: 19679769] b) Lee HG, Milner PJ, Buchwald SL. Org Lett. 2013; 15:5602-5605. [PubMed: 24138611] c) Lee HG, Milner PJ, Buchwald SL. J Am Chem Soc. 2014; 136:3792-3795. [PubMed: 24559304]

4. a) Cho EJ, Senecal TD, Kinzel T, Zhang Y, Watson DA, Buchwald SL. Science. 2010; 328:1679_ 1681. [PubMed: 20576888] b) Senecal TD, Parsons AT, Buchwald SL. J Org Chem. 2011; 76:1174-1176. [PubMed: 21235259] c) Cho EJ, Buchwald SL. Org Lett. 2011; 13:6552-6555. [PubMed: 22111687] c) Chen M, Buchwald SL. Angew Chem Int Ed. 2013; 52:11628-11631.

5. Guo Y, Shreeve JM. Chem Commun. 2007:3583-3585.Fujikawa K, Fujioka Y, Kobayashi A, Amii H. Org Lett. 2011; 13:5560-5563. [PubMed: 21955064] Fier PS, Hartwig JF. J Am Chem Soc. 2012; 134:5524-5527. [PubMed: 22397683] Prakash GKS, Ganesh SK, Jones JP, Kulkarni A, Masood K, Swabeck JK, Olah GA. Angew Chem Int Ed. 2012; 51:12090-12094.Araki K, Inoue M. Tetrahedron. 2013; 69:3913-3918.Qi Q, Shen Q, Lu L. J Am Chem Soc. 2012; 134:6548-6551. [PubMed: 22458339] During the preparation of this manuscript, the following metal-catalyzed difluoroalkylation reactions were reported, see: Min QQ, Yin Z, Feng Z, Guo WH, Zhang X. J Am Chem Soc. 2014; 136:1230-1233. [PubMed: 24417183] Ge S, Chaładaj W, Hartwig JF. J Am Chem Soc. 2014; 136:4149-4152. [PubMed: 24588379] Feng Z, Min QQ, Xiao YL, Zhang B, Zhang X. Angew Chem Int Ed. 2014; 53:1669-1673.Xiao YL, Guo WH, He GZ, Pan Q, Zhang X. Angew Chem Int Ed. 2014; 53:9909-9913.Yu YB, He GZ, Zhang X. Angew Chem Int Ed. 2014; 53:10457-10461.Ge S, Arlow SI, Mormino MG, Hartwig JF. J Am Chem Soc. 2014; 13610.1021/ ja508590kMatheis C, Jouvin K, Goossen LJ. Org Lett. 2014:16.10.1021/ol5030037Gu Y, Leng X, Shen Q. Nat Commun. 2014; 5:5405.10.1038/ncomms6405. [PubMed: 25377759] 
6. a) Wu, Y-J. Heterocyclic Scaffolds II:, Topics in Heterocyclic Chemistry. Gribble, GW., editor. Vol. 26. Springer; Berlin: 2010. p. 1-30.b) Badillo JJ, Hanhan NV, Franz AK. Curr Opin Drug Discovery Dev. 2010; 13:758-776.

7. For a discussion on bioisosteres, see: Meanwell NA. J Med Chem. 2011; 54:2529-2591. [PubMed: 21413808]

8. For examples of 3,3-difluoro-2-oxindole analogs in biological studies, see: Zhou N, Polozov AM, O'Connell M, Burgeson J, Yu P, Zeller W, Zhang J, Onua E, Ramirez J, Palsdottir GA, Halldorsdottir GV, Andresson T, Kiselyov AS, Gurney M, Singh J. Bioorg Med Chem Lett. 2010; 20:2658-2664. [PubMed: 20303752] Zhu GD, Gandhi VB, Gong JC, Luo Y, Liu XS, Shi Y, Guan R, Magnone SR, Klinghofer V, Johnson EF, Bouska J, Shoemaker A, Oleksijew A, Jarvis K, Park C, De Jong R, Oltersdorf T, Li Q, Rosenberg SH, Giranda VL. Bioorg Med Chem Lett. 2006; 16:3424-3429. [PubMed: 16644221] Podichetty AK, Faust A, Kopka K, Wagner S, Schober O, Schäfers M, Haufe G. Bioorg Med Chem. 2009; 17:2680-2688. [PubMed: 19299147]

9. a) Middleton WJ, Bingham EM. J Org Chem. 1980; 45:2883-2887.b) Singh RP, Majumder U, Shreeve JM. J Org Chem. 2001; 66:6263-6267. [PubMed: 11559172] c) Lim YH, Ong Q, Duong HA, Nguyen TM, Johannes CW. Org Lett. 2012; 14:5676-5679. [PubMed: 23101562] d) Ohtsuka Y, Yamakawa T. Tetrahedron. 2011; 67:2323-2331.e) Zhu J, Zhang W, Zhang L, Liu J, Zheng J, Hu J. J Org Chem. 2010; 75:5505-5512. [PubMed: 20704426]

10. a) Markovski LN, Pahinnik VE, Kirsanov AV. Synthesis. 1973:787-789.b) Middleton WJ. J Org Chem. 1975; 40:574-578.c) Messina PA, Mange KC, Middleton WJ. J Fluorine Chem. 1989; 42:137-143.

11. Fujiwara Y, Dixon JA, Rodriguez RA, Baxter RD, Dixon DD, Collins MR, Blackmond DG, Baran PS. J Am Chem Soc. 2012; 134:1494-1497. [PubMed: 22229949] Zhou Q, Ruffoni A, Gianatassio R, Fujiwara Y, Sella E, Shabat D, Baran PS. Angew Chem Int Ed. 2013; 52:3949-3952.Fujiwara Y, Dixon JA, O'Hara F, Funder ED, Dixon DD, Rodriguez RA, Baxter RD, Herle B, Sach N, Collins MR, Ishihara Y, Baran PS. Nature. 2012; 492:95-99. [PubMed: 23201691] Su YM, Hou Y, Yin F, Xu YM, Li Y, Zheng X, Wang XS. Org Lett. 2014; 16:2958-2961. [PubMed: 24814678] Jung J, Kim E, You Y, Cho EJ. Adv Synth Catal. 2014; 356:2741-2748.Wang L, Wei X-J, Jia W-L, Zhong J-J, Zhong L-Z, Wu L-Z, Liu Q. Org Lett. 2014; 1610.1021/o1502676yFor recent examples of C-H trifluoroethylation, see: Song W, Lackner S, Ackermann L. Angew Chem Int Ed. 2014; 53:2477-2480.Zhang H, Chen P, Liu G. Angew Chem Int Ed. 2014; 53:1017410178.

12. Hennessy EJ, Buchwald SL. J Am Chem Soc. 2003; 125:12084-12085. [PubMed: 14518981]

13. Kiser EJ, Magano J, Shine RJ, Chen MH. Org Process Res Dev. 2012; 16:255-259.

14. Choy A, Colbry N, Huber C, Pamment M, Duine JV. Org Process Res Dev. 2008; 12:884-887.

15. To the best of our knowledge, the oxidative addition of palladium to a $\mathrm{C}-\mathrm{Cl}$ bond of a difluoroalkyl chloride has not been described in the literature. The palladium-catalyzed difluoroalkylation reactions using difluoroalkyl bromides have been reported, see: ref [5g, 5i, 5k].

16. a) Grushin VV, Marshall WJ. J Am Chem Soc. 2006; 128:4632-4641. [PubMed: 16594700] b) Grushin VV, Marshall WJ. J Am Chem Soc. 2006; 128:12644-12645. [PubMed: 17002347]

17. The beneficial effects of catalyst premixing have been reported previously, see: Wolfe JP, Buchwald SL. J Org Chem. 2000; 65:1144-1157. [PubMed: 10814066] Ueda S, Su M, Buchwald SL. Angew Chem Int Ed. 2011; 50:8944-8947.Ueda S, Su M, Buchwald SL. J Am Chem Soc. 2012; 134:700-706. [PubMed: 22126442]

18. a) Joule, JA.; Mills, K. Heterocyclic Chemistry. 5. Wiley; Chichester: 2010. b) Leurs R, Bakker RA, Timmerman H, de Esch IJP. Nat Rev Drug Discovery. 2005; 4:107-120.

19. For a useful discussion on analyzing KIE, see: Simmons EM, Hartwig JF. Angew Chem Int Ed. 2012; 51:3066-3072.

20. An inverse secondary intramolecular KIE of similar magnitude has been reported for a hydroarylation reaction and was attributed to $\mathrm{sp}^{2}$ to $\mathrm{sp}^{3}$ rehybridization in an arene dearomatization step: Tunge JA, Foresee LN. Organometallics. 2005; 24:6440-6444.

21. An alternative mechanism in which $\mathrm{C}-\mathrm{C}$ bond formation proceeds via carbopalladation of the aromatic ring followed by $\beta$-H elimination cannot be excluded, see: ref [12].

Angew Chem Int Ed Engl. Author manuscript; available in PMC 2015 April 03. 


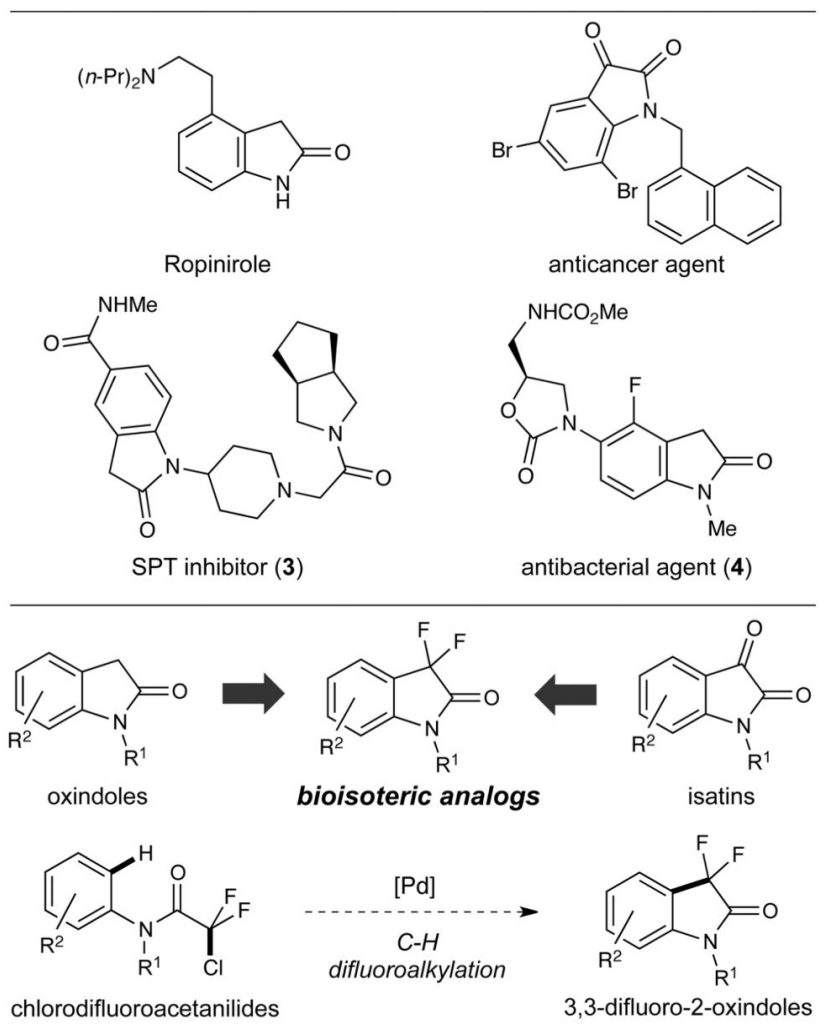

Figure 1.

Bioactive oxindoles and isatins (top), 3,3-difluoro-2-oxindoles as bioisosteric analogs of oxindoles and isatins and their proposed synthesis from chlorodifluoroacetanilides (bottom). 
Intramolecular: (eq 1)<smiles>[2H]c1ccccc1N(C)C(=O)C(F)(Cl)C(F)(F)Cl</smiles>

$1 \mathrm{a}-d_{1}$

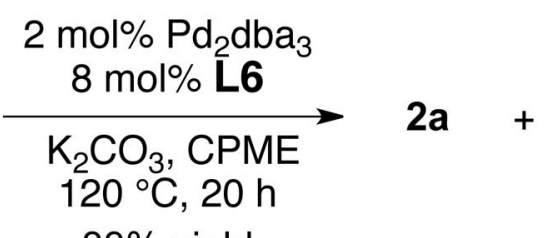

$83 \%$ yield<smiles>[2H]c1cccc2c1N(C)C(=O)C2(F)F</smiles>

$2 a-d_{1}$

$$
k_{H} / k_{D}=0.79 \pm 0.05
$$

Intermolecular: (eq 2)<smiles>Cc1cccc(N(C(=O)[18F])C(=O)C(F)(F)F)c1</smiles>

$1 \mathrm{a}-d_{5}$

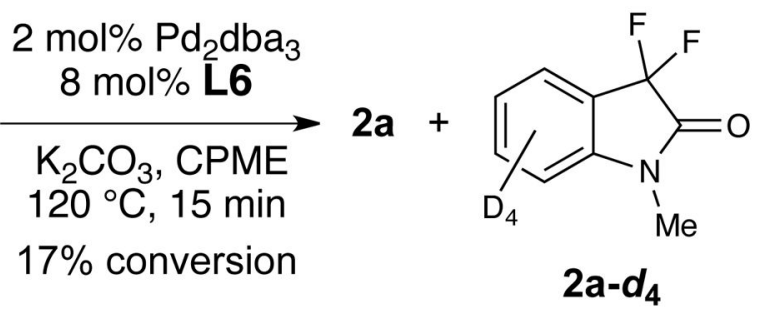

$k_{\mathrm{H}} / k_{\mathrm{D}}=1.01 \pm 0.06$

Scheme 1.

Observed kinetic isotope effects 

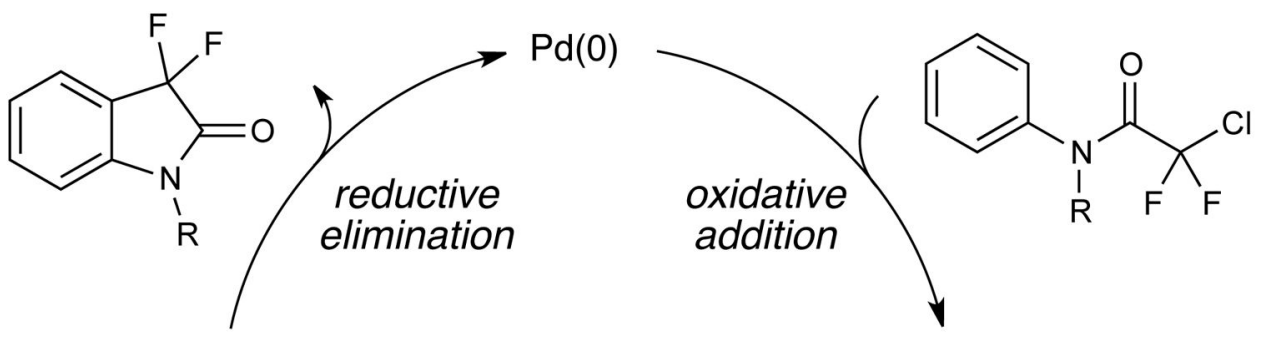<smiles>[R]N1C(=O)C(F)(F)[Te]c2ccccc21</smiles><smiles>[R]N(C(=O)C(F)(F)[R]Cl)c1ccccc1</smiles><smiles>CCCCOC(=O)OCOCCO</smiles><smiles>[R]N1C(=O)C(F)(F)[R8]C2[CH-]C=CC=C21</smiles>

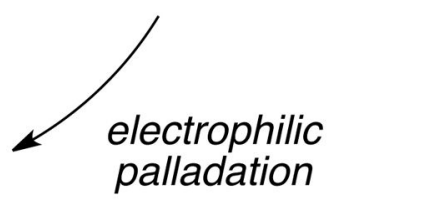

Scheme 2.

Proposed catalytic cycle (the ligand was omitted for clarity) 


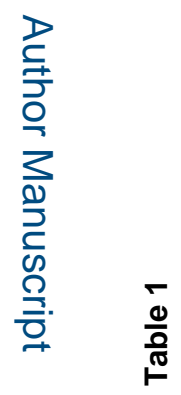

를

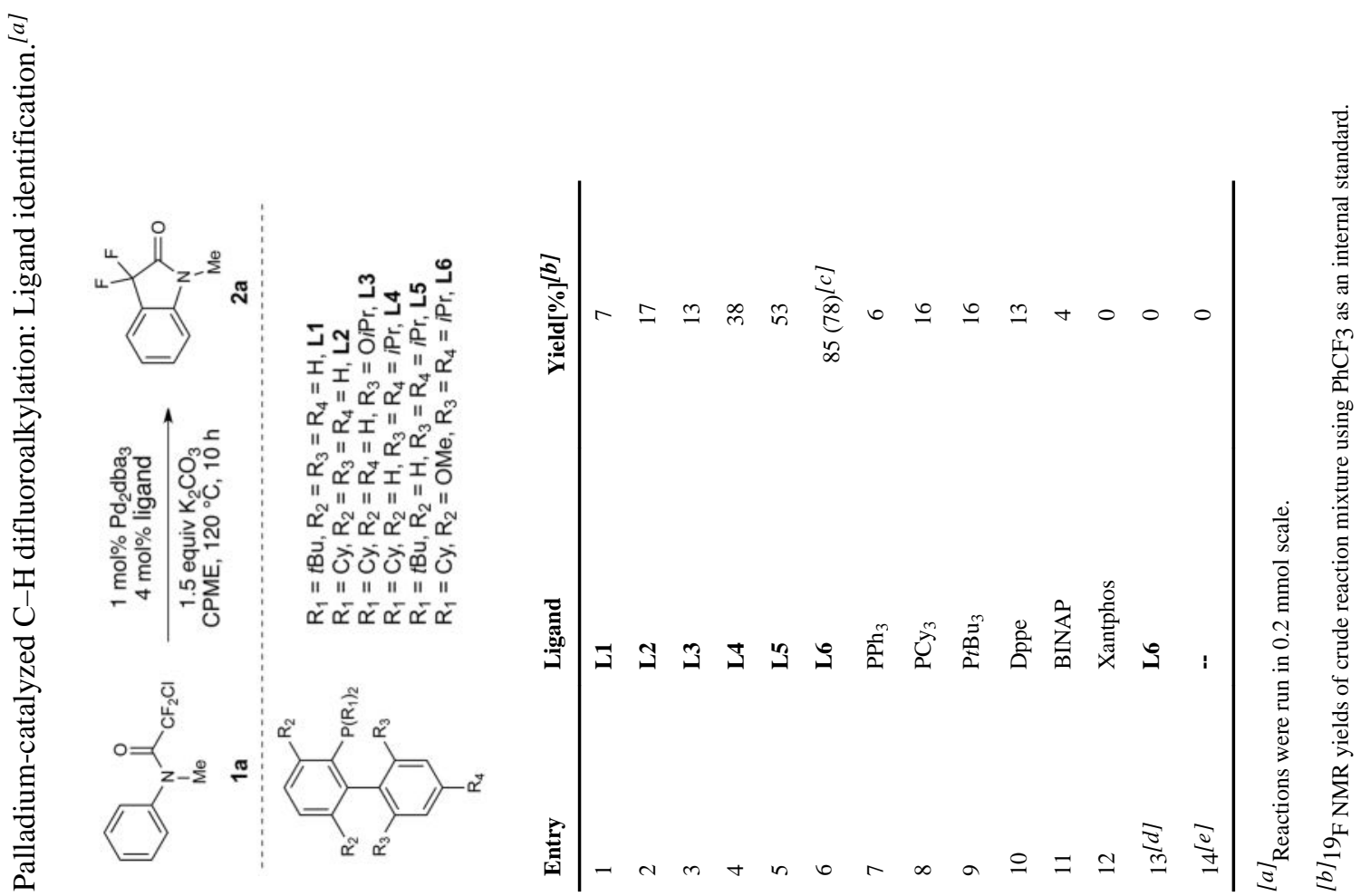




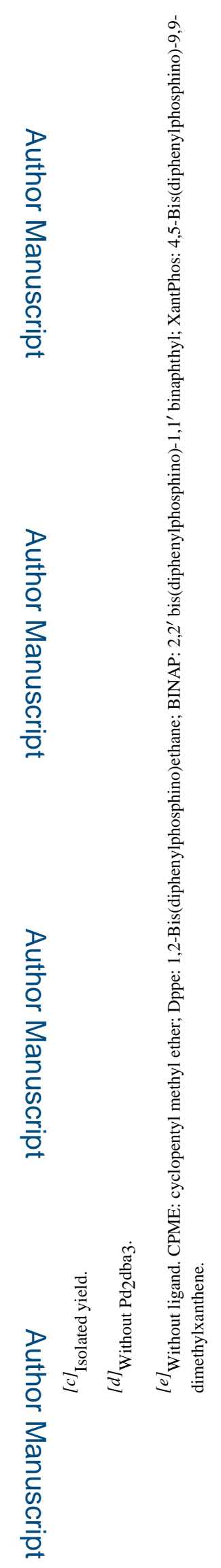

Angew Chem Int Ed Engl. Author manuscript; available in PMC 2015 April 03. 
Table 2

Palladium-catalyzed C-H difluoroalkylation of arenes ${ }^{[a]}$.

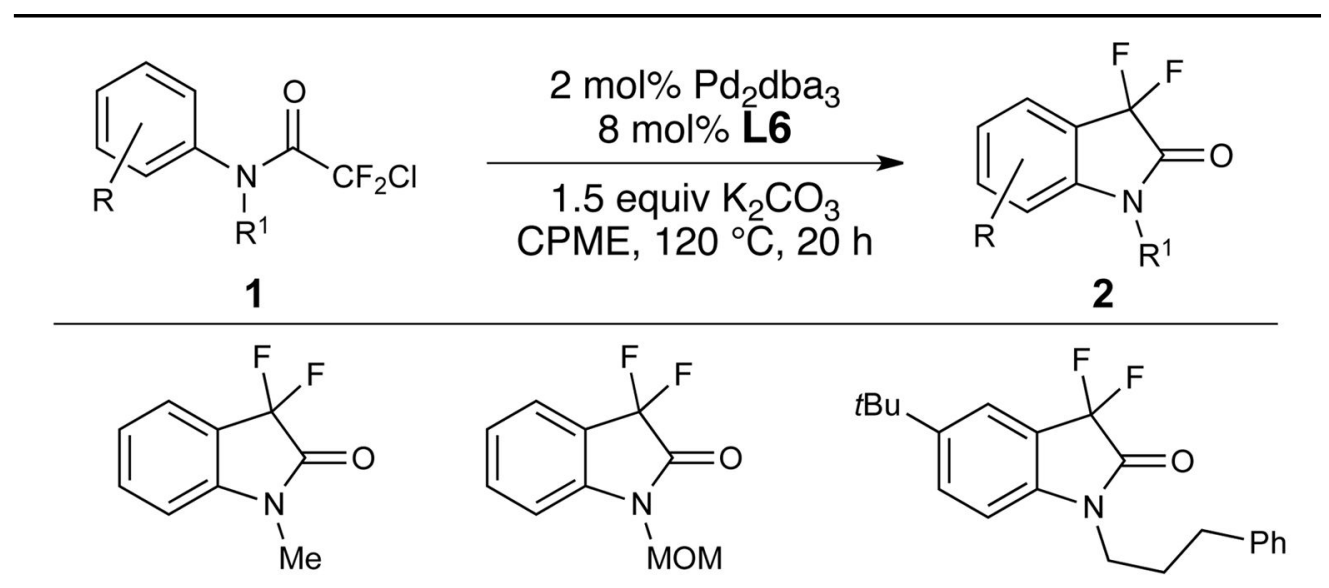

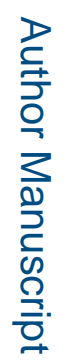<smiles>COc1cc2c(c(OC)c1OC)C(F)(F)C(=O)N2CCN(C)C</smiles>

2d, $66 \%$

2b, $66 \%$

2c, $80 \%$

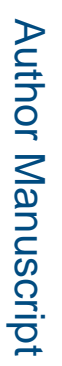<smiles>COC(=O)c1ccc2c(c1)C(F)(F)C(=O)N2C</smiles>

$2 \mathrm{~g}, 76 \%$<smiles>COCCN1C(=O)C(F)(F)c2cc(N3CCOCC3)ccc21</smiles><smiles>CC(C)N1C(=O)C(F)(F)c2cc(OC(F)(F)F)ccc21</smiles>

2e, $62 \%$

2f, $75 \%$<smiles>CCNC(=O)c1ccc2c(c1)C(F)(F)C(=O)N2CC(OC)OC</smiles>

$2 \mathbf{i}, 81 \%$

\section{$21,81 \%$}

\footnotetext{
${ }^{[a]}$ Yields of isolated product are an average of two runs on a $1.0 \mathrm{mmol}$ scale.

${ }^{[b]}$ Reaction conditions: $\mathrm{Pd}_{2} \mathrm{dba} 3$ (1 mol\%), L6 (4 mol\%), $10 \mathrm{~h}$.
} 
Table 3

Palladium-catalyzed C-H difluoroalkylation of heteroarenes ${ }^{[a]}$.

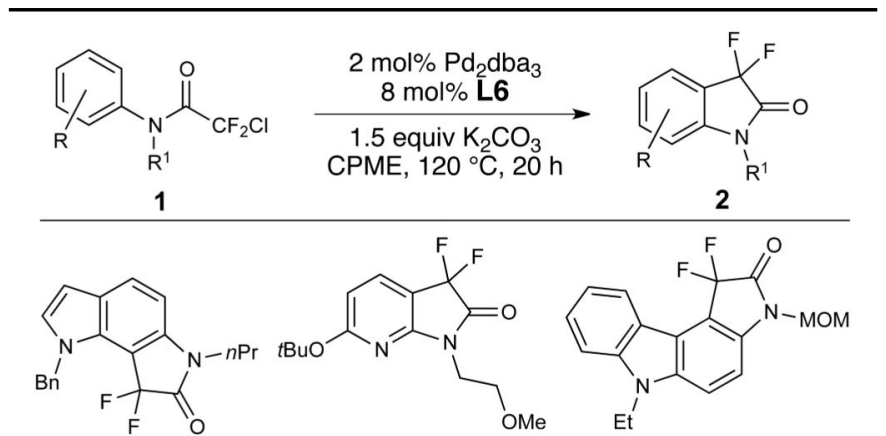

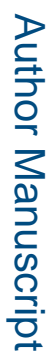

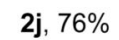

2 k, $70 \%$

2I, $91 \%$

$5.6: 1$, r.r.

1.7:1, r.r.

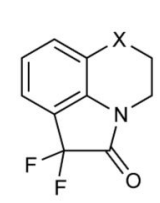<smiles>O=C1N2CCCc3cccc(c32)C1(F)F</smiles><smiles>O=C1CCN2C(=O)C(F)(F)c3cccc1c32</smiles><smiles>O=C1N2Cc3ccccc3-c3cccc(c32)C1(F)F</smiles>

$\mathrm{X}=\mathrm{CH}_{2}, \mathbf{2 m}, \mathbf{8 5} \%$ $X=O, 2 n, 52 \%$

2o, $95 \%$

2p, $53 \%$

2q, $65 \%$
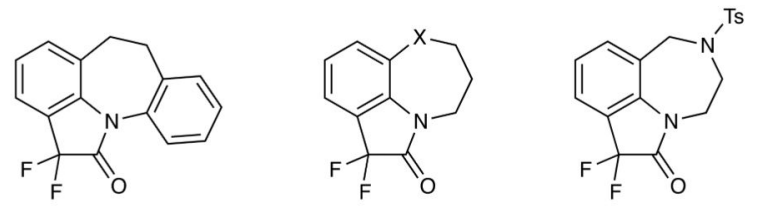

2s, $64 \%$

$\mathrm{X}=\mathrm{CH}_{2}, \mathbf{2 r}, 70 \%$

2y, $71 \%$

$X=0,2 t, 80 \%$ [b]

$\mathrm{X}=\mathrm{S}, \mathbf{2 x}, \mathbf{7 4 \%}$

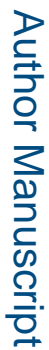

${ }^{[a]}$ Yields of isolated product are an average of two runs in $1.0 \mathrm{mmol}$ scale.

${ }^{[b]}$ Reaction was conducted in $5.0 \mathrm{mmol}$ scale.

${ }^{[c]}$ r.r.: regioisomeric ratio. 